\title{
Nanoscale
}

Cite this: Nanoscale, 2013, 5, 7328

Received 3rd January 2013

Accepted 15th May 2013

DOI: $10.1039 / c 3 n r 00024 a$

www.rsc.org/nanoscale

\section{Immobilized silver nanoparticles enhance contact killing and show highest efficacy: elucidation of the mechanism of bactericidal action of silveri}

\author{
Shekhar Agnihotri, ${ }^{a}$ Soumyo Mukherji ${ }^{a b c}$ and Suparna Mukherji*ad
}

\begin{abstract}
Antimicrobial materials with immobilized/entrapped silver nanoparticles (AgNPs) are of considerable interest. There is significant debate on the mode of bactericidal action of AgNPs, and both contact killing and/or ion mediated killing have been proposed. In this study, AgNPs were immobilized on an amine-functionalized silica surface and their bactericidal activity was studied concurrently with the silver release profile over time. This was compared with similar studies performed using colloidal AgNPs and $\mathrm{AgCl}$ surfaces that released $\mathrm{Ag}$ ions. We conclude that contact killing is the predominant bactericidal mechanism and surface immobilized nanoparticles show greater efficacy than colloidal AgNPs, as well as a higher concentration of silver ions in solution. In addition, the AgNP immobilized substrate was used multiple times with good efficacy, indicating this immobilization protocol is effective for retaining AgNPs while maintaining their disinfection potential. The antibacterial surface was found to be extremely stable in aqueous medium and no significant leaching ( $1.15 \%$ of total silver deposited) of the AgNPs was observed. Thus, immobilization of AgNPs on a surface may promote reuse, reduce environmental risks associated with leaching of AgNPs and enhance cost effectiveness.
\end{abstract}

\section{Introduction}

The concept of using silver nanoparticles (AgNPs) as an antimicrobial agent has been widely documented and significant research has been published recently. ${ }^{1-3}$ AgNPs are known to possess oligodynamic action, can kill antibiotic-resistant microbes, ${ }^{\mathbf{1}}$ and have low cytotoxicity towards mammalian cells. ${ }^{2}$ Nowadays, silver nanoparticles are used for medical applications as coatings in bone prostheses and surgical devices, as well as silver impregnated catheters, infusion systems and dental composites. ${ }^{4,5}$ In addition, there are numerous consumer products utilizing the antimicrobial properties of AgNPs, such

\footnotetext{
${ }^{a}$ Centre for Research in Nanotechnology and Science, Indian Institute of Technology Bombay, Powai, Mumbai 400076, India

${ }^{b} \mathrm{WRCBB}$, Department of Biosciences and Bioengineering, Indian Institute of Technology Bombay, Powai, Mumbai 400076, India

${ }^{c}$ Centre of Excellence in Nanoelectronics, Indian Institute of Technology Bombay, Powai, Mumbai 400076, India

${ }^{d}$ Centre for Environmental Science and Engineering, Indian Institute of Technology Bombay, Powai, Mumbai 400076, India. E-mail: mitras@iitb.ac.in; Fax: +91-222576-4650; Tel: +91-22-2576-7854

$\dagger$ Electronic supplementary information (ESI) available: Photographic image of silanization chamber; FEG-TEM image to show particle distribution of as-synthesized silver nanoparticles; photographic image of pristine amino-silanized glass and AgNPs immobilized glass; batch reactor fabrication for disinfection and silver release studies; surface coverage of silver nanoparticle immobilized glass substrate; and EDX analysis of the treated bacterial (E. coli) cells. See DOI: 10.1039/c3nr00024a
}

as cosmetics, air/water filters, food packaging containers and textiles. $^{6}$

However, there are certain challenges that may restrict their maximal use as an efficient antimicrobial agent. In the absence of any support, colloidal AgNPs tend to form aggregates in the aqueous phase, which gradually diminishes their efficacy in long term use..$^{7-10}$ The leaching of silver nanoparticles and their discharge into waterways may also adversely affect aquatic life..$^{\mathbf{8 1 1}, 12}$ Therefore, immobilization of silver nanoparticles on a surface would allow the realization of an effective disinfection system with controlled silver release while reducing the associated environmental threats. For practical antibacterial applications, immobilized nanoparticles could be a promising approach to ensure cost effectiveness by facilitating recovery of AgNPs $^{12,13}$ and enabling them to be reused multiple times.

Bactericidal action has been reported for silver nanoparticles on various structures ${ }^{\mathbf{3 , 8 , 1 4 - 1 9}}$ used as a support matrix for either anchoring or immobilizing the silver nanoparticles. Among them, silver-silica based hybrid nanomaterials are becoming increasingly popular as they provide different functionalities for anchoring silver nanoparticles by allowing various surface modifications. Since the surface of silica terminates in either siloxane groups (-Si-O-Si-) with oxygen atoms on the surface as well as silanol groups $(-\mathrm{Si}-\mathrm{OH})$, covalent grafting of organic polymers with these moieties can provide different types of modified silica surfaces. ${ }^{20}$ Silanization is one of the most commonly used techniques for silica surface modification, where the desired surface functional group can be tuned by 
using different types of organic polymers, i.e., organosilanes. Some examples include the use of aminosilane and mercaptosilane, which have been extensively studied for silver nanoparticle immobilization on silica surfaces. ${ }^{21,22}$

For an ideal antimicrobial design, ${ }^{23,24}$ the material used should possess the ability to delay/prevent the formation of a biofilm and cause inactivation of microbes either through release of an antimicrobial agent or through a direct contactkilling mechanism. Interestingly, silver nanoparticles have demonstrated all these properties ${ }^{23-25}$ and therefore serve as a promising candidate for improved antimicrobial applications. In general, the mode of antibacterial mechanism of AgNPs is attributed to the release of silver ions, which may rupture the cell wall, cause protein denaturation, block cell respiration, and finally cause microbial death., ${ }^{2,10} \mathrm{~A}$ few researchers have hypothesized that the contact killing mechanism also contributes to their enhanced antimicrobial effect, although killing is mainly governed by the silver release mechanism. ${ }^{3,10,26}$ In contrast, the antimicrobial nature of a few silver-containing nanomaterials is believed to be only through the contact killing mechanism, which contributes an even greater potential lethality when bacteria come in contact with them..$^{25,27}$ However, for an efficient antimicrobial activity, surfaces having both biocidal release and the contact mode are always preferred over any one of the individual modes. ${ }^{28,29}$

In this study, an attempt was made to immobilize silver nanoparticles on a functionalized silica surface, which could emerge as a promising antimicrobial material for water disinfection purposes, against both Gram-positive and Gram-negative bacterial strains. The fabrication of an antibacterial surface is based on an amine-functionalized silica substrate using 3-(2aminoethylaminopropyl)trimethoxysilane (AEAPTMS) as a crosslinker molecule, on to which silver nanoparticles were anchored/immobilized. The disinfection potential of this antibacterial surface was evaluated against three bacterial strains i.e., Escherichia coli (two strains) and Bacillus subtilis (one strain) in a $100 \mathrm{ml}$ batch reactor, having an initial bacterial concentration of either $10^{3}$ or $10^{5} \mathrm{CFU} \mathrm{ml}{ }^{-1}$. The efficacy of the asfabricated antimicrobial surface was evaluated after being reused eleven times in concurrence with the silver release profile over time. Finally, the mode of antibacterial action of immobilized AgNPs was investigated by comparing its disinfection profile and silver release studies with other sources of silver ions i.e. $\mathrm{AgCl}$, pure $\mathrm{Ag}$ and colloidal AgNPs.

\section{Experimental}

\subsection{Materials and methods}

Silver nitrate $\left(\mathrm{AgNO}_{3},>99.9 \%\right.$ pure $)$, sodium borohydride $\left(\mathrm{NaBH}_{4},>99 \%\right.$ purity) and trisodium citrate (TSC), were purchased from Merck (India). Aminosilane used for the immobilization protocol, i.e., 3-(2-aminoethylaminopropyl)trimethoxysilane (AEAPTMS), was procured form Sigma-Aldrich (USA). Ethyl alcohol, acetic acid, nitric acid, hydrochloric acid and sulfuric acid were obtained from Merck (Germany) and were used at the desired dilutions. All reagents supplied were of analytical grade and were used as received.
The disinfection experiments were carried out on Gram negative bacterial strains, E. coli MTCC 443 (ATCC 25922), MTCC 739 (ATCC 10536) and a Gram-positive bacterial strain B. subtilis MTCC 441 (ATCC 6633), which were procured from the Institute of Microbial Technology (Chandigarh, India). Nutrient media (Himedia Laboratories Ltd., Mumbai) were used for the growth of bacterial strains in liquid broth culture, while Eosin-methylene blue (EMB) agar (Himedia Laboratories Ltd., Mumbai) was employed as the differential media during plate culture studies.

\subsection{Synthesis of silver nanoparticles}

All experiments were performed in the dark to prevent photodecomposition of $\mathrm{AgNO}_{3}$. Silver nanoparticles were formed using $\mathrm{NaBH}_{4}$ and trisodium citrate (TSC) as the reducing and capping agent, respectively at the required stoichiometric ratios. Briefly, silver nitrate was introduced into a mixed solution of $\mathrm{NaBH}_{4}$ and TSC, under constant stirring, at room temperature, such that a molar ratio of $1: 2$ was maintained between silver and $\mathrm{NaBH}_{4}$. Immediately, the solution turned to a light yellow and finally, to a deep wine red indicating the formation of silver nanoparticles. The resulting solution was continuously stirred for 30 minutes so as to ensure the formation of silver nanoparticles. Later, silver nanoparticles were centrifuged (12000 rpm, $15 \mathrm{~min})$, washed three times with deionized water to remove the unreacted reductant and impurities, and stored at $4{ }^{\circ} \mathrm{C}$.

\subsection{Surface modification of glass: immobilization protocol}

Glass substrates $\left(1 \times 1 \mathrm{~cm}^{2}\right.$ dimension $)$ were thoroughly cleaned by immersion in an acid mixture consisting of methanol-HCl $(1: 1 \mathrm{v} / \mathrm{v})$ for 30 minutes followed by Piranha treatment ( $3: 1$, conc. $\mathrm{H}_{2} \mathrm{SO}_{4}-30 \% \mathrm{H}_{2} \mathrm{O}_{2}$ ), and were stored for up to two weeks. For grafting amino-functional groups on the surface of glass, a silanization procedure was adopted using a customized silanization chamber (Fig. S1†). In brief, silanol ( $\mathrm{Si}-$ $\mathrm{OH})$ sites on the glass surface were created by acid hydrolysis using sulphochromic acid treatment for 30 minutes, and subsequently the substrates were vacuum dried at $120^{\circ} \mathrm{C}$ for 1.5 hours. The dehydrated substrates were dipped in a $2 \%$ AEAPTMS solution (prepared using absolute ethanol and acetic acid $(5: 3 \mathrm{v} / \mathrm{v})$ as solvent) for 30 minutes, rinsed with excess ethanol and finally dried in an argon atmosphere. Condensation of siloxane bonds was carried out by heating the substrates at $120{ }^{\circ} \mathrm{C}$ for 30 minutes in argon atmosphere. Subsequently, the silanized glass slides were incubated in AgNP suspension overnight and thoroughly rinsed. Finally, AgNP immobilized glass substrates (AgNP-glass) were sonicated for 5 minutes to ensure complete removal of loosely bound AgNPs from the modified glass surface. Fig. 1 demonstrates immobilization of silver nanoparticles on the amine-functionalized glass surface.

\subsection{Sample characterization}

UV-Vis extinction spectra were recorded using a spectrophotometer (Perkin-Elmer Lambda 35, USA) in absorbance mode (range $200-800 \mathrm{~nm}$ ) at the desired dilution of AgNP colloids. For 


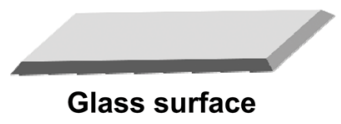

Glass surface (i) Sulphochromic acid treatment

(ii) Silanol group stabilization

(a)
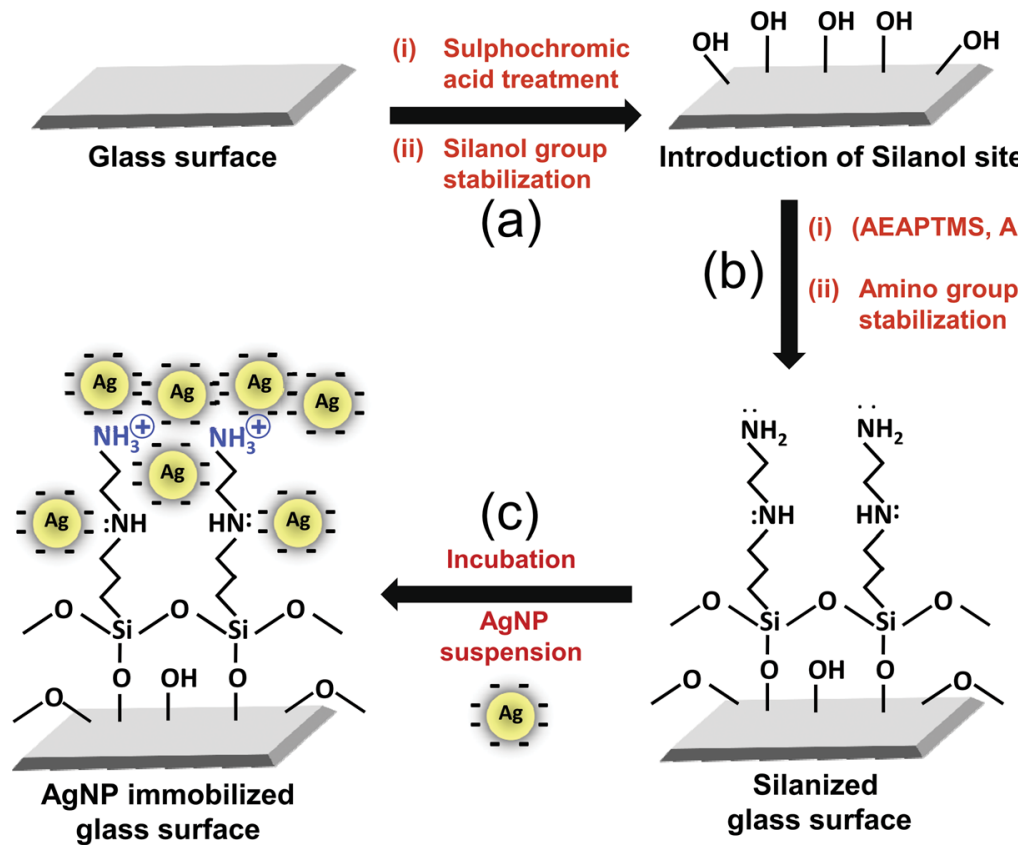

Introduction of Silanol sites

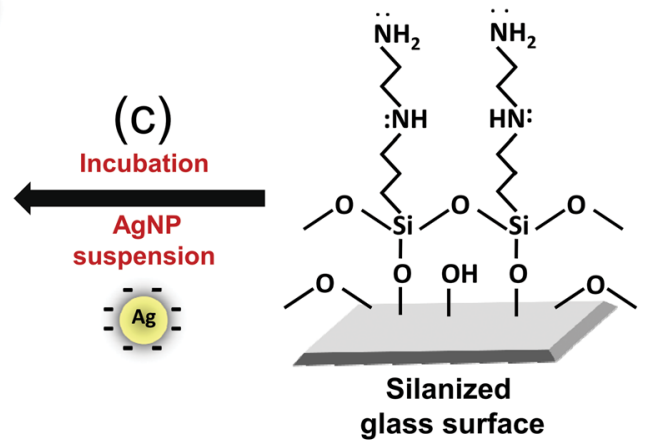

Fig. 1 Schematic representation of the silanization procedure, followed by immobilization of silver nanoparticles on the amine-functionalized glass surface (a) Additional silanol (Si-OH) sites were generated by sulphochromic acid treatment and stabilized at $120^{\circ} \mathrm{C}, 1.5$ hours under Ar atm. (b) Substrates were treated with 3-(2aminoethylaminopropyl) trimethoxysilane solution (2\% AEAPTMS, $30 \mathrm{~min}$ ) and condensation of siloxane bonds $\left(120^{\circ} \mathrm{C}, 30 \mathrm{~min}\right)$ was achieved. (c) Immobilization was mediated by overnight incubation of the amine-functionalized glass substrate in silver nanoparticle solution.

determining the size and morphology of silver nanoparticles using FEG-TEM (JEOL JEM 2100F, Japan), a $10 \mu$ l AgNP sample was placed on a carbon-coated copper grid and was allowed to dry at room temperature overnight. The sample-loaded copper grid was placed under an IR-lamp for 15 minutes to ensure complete dryness. The crystallinity of the nanoparticles was characterized using an X-ray diffractometer (XRD, PANalytical X'pert PRO, The Netherlands) employing $\mathrm{CuK}_{\alpha}$ radiation. The as prepared colloidal AgNPs were drop cast on the silanized glass surface, followed by drying in vacuum overnight. The sample was scanned over a $2 \theta$ range of $20-90^{\circ}$ with a scan speed of $0.017^{\circ}$ per $25.18 \mathrm{~s}$. The slow scan speed was employed to get the desired XRD signals, and to detect the presence of any impurities on AgNPs. The zeta potential of the AgNP colloids was measured using a zeta potential analyzer (Zeta pals, Brookhaven, USA) by sonicating for $90 \mathrm{~s}$ to minimize aggregation of nanoparticles and three zeta potential measurements were performed for two independent samples. For AFM analysis, the AgNP-glass substrates were dried for at least 24 hours in a vacuum desiccator. Imaging was done under a silicon nitride AFM cantilever (tip radius, $10 \mathrm{~nm}$ ) using Nanoscope IV multimode AFM (Veeco Instruments Inc., USA) in tapping mode. At least three different areas of two independent samples were scanned at a scan rate of $1.0 \mathrm{~Hz}$. The chemical state of the AgNP-glass surface was analyzed by an X-ray photoelectron spectrometer (XPS, Thermo VG Scientific MultiLab, USA). A microfocused monochromatic (Al Ka $=1486.6 \mathrm{eV}) \mathrm{X}$-ray source was operated at $250 \mathrm{~W}$ with a step size of $0.1 \mathrm{eV}$ to collect high resolution spectra. The deconvolution, curve fitting, and background subtraction was done using XPS Peak 4.1 software. The wettability of various glass substrates was measured using the sessile drop method with a static contact angle Goniometer (GBX Digidrop, France) employing deionized water as probe liquid at room temperature. In brief, a $2 \mu \mathrm{l}$ drop of deionized water was dropped from a calibrated micro-syringe over each substrate (taken in triplicate) at three different locations, i.e., a total of nine measurements were then averaged. For comparison, the water contact angle was measured after each step of the surface modification procedure, i.e. after silanol site generation, after the silanization procedure and after AgNP immobilization.

\subsection{Antibacterial tests}

Strain specific studies for bactericidal effect were done using three bacterial strains, E. coli MTCC 443, E. coli MTCC 739, and B. subtilis MTCC 441. Two sets of disinfection studies were done using deionized water and phosphate buffer $(\mathrm{pH}$ 7.4, $1.25 \mathrm{mM}$ $\mathrm{KH}_{2} \mathrm{PO}_{4}, 2.5 \mathrm{mM} \mathrm{K} \mathrm{HPO}_{4}, 4.7 \mathrm{mM} \mathrm{Na} \mathrm{HPO}_{4}$, supplemented with $0.4 \%$ glucose) as the aqueous phase. A chlorine-free phosphate buffer medium was used in order to avoid $\mathrm{AgCl}$ formation during silver ion release from the antimicrobial surface. All disinfection studies were performed independently in a $100 \mathrm{ml}$ batch reactor (Fig. S4 $\dagger$ ) having an initial bacterial concentration of either $\sim 10^{3}$ or $\sim 10^{5} \mathrm{CFU} \mathrm{ml}^{-1}$, determined using plate count. The bacterial cells grown up to the end of log phase were harvested by centrifugation $\left(10000 \mathrm{rpm}\right.$ at $4{ }^{\circ} \mathrm{C}, 10$ min) and the pellet obtained was washed thrice and resuspended in $2 \%$ phosphate buffer. Thereafter, the bacterial population was adjusted to an optical density (OD) of one, which corresponds to a cell concentration of $\sim 10^{9} \mathrm{CFU} \mathrm{ml}^{-1}$, using a spectrophotometer. Disinfection studies were done at fixed 
initial concentrations by taking aliquots from the batch reactor at desired time intervals, plating on agar plates, and incubating at $37{ }^{\circ} \mathrm{C}$ for 24 hours to obtain viable counts. All experiments were conducted in duplicate.

\subsection{Silver release profile}

For silver release studies, similar batch reactors containing an AgNP-glass substrate were used, however bacterial cells were not added. In this experiment, fresh DI water was filled into the reactor under clean lab conditions. A specific volume of sample was taken out at desired intervals with a sterilized syringe and was analyzed after acid digestion. This was followed by appropriate dilution of the test samples for the measurement of silver release using ICP-AES (see ESI, S1†).

\subsection{Antimicrobial efficacy of the AgNP immobilized substrate}

A single substrate was used multiple times for the disinfection study and silver release studies, so as to indicate the efficacy of AgNP immobilization on the glass surface. The disinfection and silver release kinetics after every usage was evaluated to determine the mode of antibacterial action of the AgNP-glass substrate. In this experiment, the same antibacterial substrate (AgNP-glass, $1 \times 1 \mathrm{~cm}^{2}$ dimension) was used alternately for the disinfection study and silver release study repeatedly. The $n$th (where, $n=1,3,5,7, \ldots$ ) experiment denotes a disinfection study and the $(n+1)$ th experiment denotes a silver release study. The time period between each antibacterial study and silver release study was in the range of 10-12 hours. After removing the substrate from the aqueous medium, it was completely dried under an inert environment ( $\mathrm{N}_{2}$ gas purging) and was subsequently stored under vacuum until further use.

To assess the role of continuous release of silver ions in disinfection, a silver plate ( $\geq 99.9 \%$ purity) and chloridized silver plate was compared with an AgNP-glass substrate (all $1 \times$ $1 \mathrm{~cm}^{2}$ dimensions). While a pure "silver plate" may cause uncontrolled release of silver ions, a "chloridized silver plate" is expected to facilitate controlled release of silver ions due to the low aqueous solubility of AgCl. The chloridization of the silver plate was done by incubating in $0.1 \mathrm{M}$ sodium hypochlorite overnight followed by alternately washing and sonicating thrice in deionized water. The silver release profile was measured in these cases as well.

\subsection{Comparative disinfection performance of silver nanoparticles in their immobilized and colloidal form}

All other experimental conditions were kept same except that in the latter case, a AgNP suspension was used in place of AgNPglass substrate and, the reactor was gently shaken at regular intervals to minimize aggregation and settlement of AgNPs during the study. For both cases, the amount of silver nanoparticles in the $100 \mathrm{ml}$ reactor was kept constant i.e., $3.07 \times$ $10^{-2} \mathrm{mg}$. Since both the immobilized and colloidal nanoparticles came from the same synthesis procedure, they were effectively of same size and morphology. In order to investigate the mode of the antibacterial action, the treated $E$. coli cells were subjected to a series of pretreatment procedures, following Morones et al. ${ }^{\mathbf{1 0}}$ with a few modifications, and were examined under FEG-TEM. For FEG-SEM analysis (JEOL JSM-7600F, Japan) samples were prepared on carbon coated copper grids without any conductive coating (gold/platinum sputtering) as it may hide the real morphology of the substrates.

\section{Results and discussion}

Fig. 2 shows the UV-Vis absorption spectrum of AgNPs with a sharp surface plasmon resonance (SPR) peak at $396 \mathrm{~nm}$. As observed through FEG-TEM micrographs, the mode mean diameter and count mean diameter of silver nanoparticles were found to be $8.6 \pm 1.2 \mathrm{~nm}$ and $8.4 \pm 0.6 \mathrm{~nm}$, respectively, with a size distribution ranging from 6.3 to $10.8 \mathrm{~nm}$ (Fig. S2†). All nanoparticles were found to be spherical in shape and were well segregated. The average crystallite size of AgNPs estimated through XRD (using Scherrer's equation) was $8.9 \pm 0.7 \mathrm{~nm}$, which corroborates with the particle size obtained through FEGTEM. ${ }^{14}$ The XRD pattern demonstrated two broad peaks at $38.1^{\circ}$ and $44.2^{\circ}$, which can be indexed to the (111) and (200) reflections of metallic silver (JCPDS file no. 04-0783). Since no other peaks were identified, the AgNPs formed were essentially pure with high crystallinity. The observed zeta potential value $(-29.3 \mathrm{mV})$ for the citrate capped silver nanoparticles is close to the values reported in the literature for stable nanoparticle suspensions comprised of nanoparticles with a negative charge on their surface. ${ }^{30}$

\subsection{Silver nanoparticle immobilization on AEAPTMS- functionalized silica substrate}

A glass (silica) substrate was surface-functionalized with amine groups using 3-(2-aminoethylaminopropyl)trimethoxy silane (AEAPTMS) as a crosslinker molecule employing a series of steps as illustrated in Fig. 1. Joshi et al. ${ }^{31}$ established that uniform silanol groups $(\mathrm{Si}-\mathrm{OH})$ can be produced on a glass surface by acidic hydrolysis, which ultimately form siloxane ( $\mathrm{Si}-\mathrm{O}-\mathrm{Si}$ ) bonds within the silanol sites on the glass surface, as well as between aminosilane molecules through polycondensation. Upon reacting with the negatively charged AgNP suspension, the silver nanoparticles were firmly immobilized on the surface-exposed amino groups through covalent bond and/or electrostatic interactions, and van der Waals forces. ${ }^{32}$ Here, the existence of $\mathrm{NH}_{3}{ }^{+}$is attributed to proton transfer (in the presence of adsorbed water) from the surface $-\mathrm{OH}$ groups to the amine groups of silane. ${ }^{33,34}$ This positive charge in turn is expected to be best suited for deposition of citrate stabilized AgNPs. ${ }^{35}$ The water content during the immobilization protocol was precisely optimized since an absence of water leads to the formation of incomplete silane layers, while an excess of it gives a non-uniform silane film due to pre-deposition oligomerization. ${ }^{31} \mathrm{~A}$ pH range of 3.2 to 3.7 was maintained during the silanization step so as to orient the amine groups away from the glass surface, ${ }^{36}$ and to facilitate interaction between the AgNPs and silane moieties. ${ }^{31}$ The surface underwent a thorough water rinse and ultrasonication before further use. 


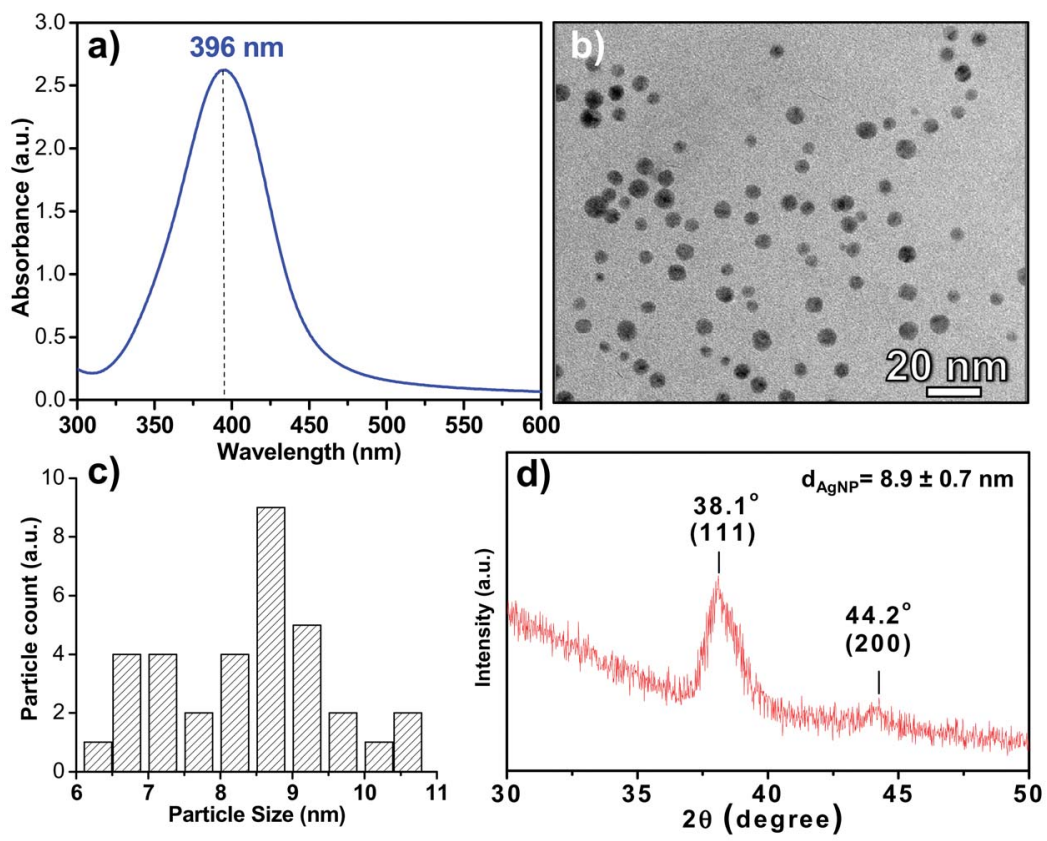

Fig. 2 Representative (a) UV-Vis extinction spectra and (b) FEG-TEM image of as synthesized silver nanoparticles. (c) Histogram for the particle size distribution with average particle size $8.6 \pm 1.2 \mathrm{~nm}$ and a size range of 6.3 to $10.8 \mathrm{~nm}$, derived by counting over multiple images (no. of counts: 476). (d) XRD pattern of silver nanoparticles.

\subsection{Characterization studies}

A significant difference was observed in the visual appearance of the silica substrate before and after AgNP deposition (Fig. S3 $\dagger$ ). The color of AgNP-glass changed from colorless to a yellow tint arising from AgNPs coating the silanized glass surface. The surface morphology of AgNP immobilized glass substrates was analyzed using scanning electron microscopy (FEG-SEM), which showed that AgNPs were firmly immobilized onto the silanized surface and almost every section of the glass was covered by uniformly dispersed silver nanoparticles (Fig. 3a). AgNPs were uniformly dispersed having a size range of 10-15 nm with a few AgNP clusters of 40-60 nm. The apparent increase in size of the immobilized nanoparticles compared to that of the nanoparticle suspension observed through TEM may be due to specimen charge-up occurring in the non-conducting silica substrate in the absence of conductive coating. Specimen charge-up may prevent the normal emission of secondary electrons from the specimen surface and may result in abnormal contrast and edge effects which may cause such artifacts at large magnification. The micrograph revealed that silver nanoparticles were uniformly dispersed without significant aggregation on both surfaces of the substrate. This indicated successful functionalization of the substrate and strong surface immobilization of AgNPs. As shown by Fig. 3b, multilayer deposition of silver nanoparticles on the glass substrate was also observed along with monolayer formation, possibly due to non-covalent interactions between AgNPs and the primary and secondary amine present in the aminosilane used in this study. A predeposition oligomerization of aminosilane may also contribute to the multilayered structure. Further, semi-quantitative estimation of the surface composition, as determined by EDX, showed that $35.6 \%$ (\% by wt) of the antimicrobial surface was occupied with elemental silver (Fig. 3d, left panel). Elemental mapping (Fig. 3d, right panel) done for a selected region $\left(5 \times 5 \mu^{2}\right)$, also indicated high deposition of silver (blue) with the presence of other elements, i.e., carbon (yellow), oxygen (green), and silicon (red). Although silicon and oxygen should be present throughout for a silica substrate, they are only detected as specific spots since at the reduced dwell time of $5 \mu$ s employed for elemental mapping they often fall below the detection limit. Ag detection limit is much higher than for $\mathrm{Si}, \mathrm{O}$ and $\mathrm{C}$ due to its higher atomic number, hence, $\mathrm{Ag}$ spots are prevalent on this substratum.

The topographical features of the AgNP-glass surface were also characterized using AFM. The root-mean-square (rms) roughness of the amine-functionalized glass surface was measured as $0.4 \mathrm{~nm}$, which increased significantly to $3.2 \mathrm{~nm}$ after the immobilization of silver nanoparticles (Fig. 4). Moreover, it was demonstrated that all nanoparticles were present in a well segregated manner with a few nano clusters, as also observed during FEG-SEM analysis. Further it may be concluded that the nanoparticles retained their charged surfaces during immobilization and possibly afterwards as well. This minimized the possibility of aggregation of AgNPs due to the formation of hydrogen bonds between the carboxylate groups on closely packed neighboring particles. ${ }^{35}$

While calculating the particle size using AFM analysis in tapping mode, the particle diameter was overestimated due to an intrinsic property of AFM, commonly termed 'sample-tip convolution'. To resolve this, the true particle diameter was 

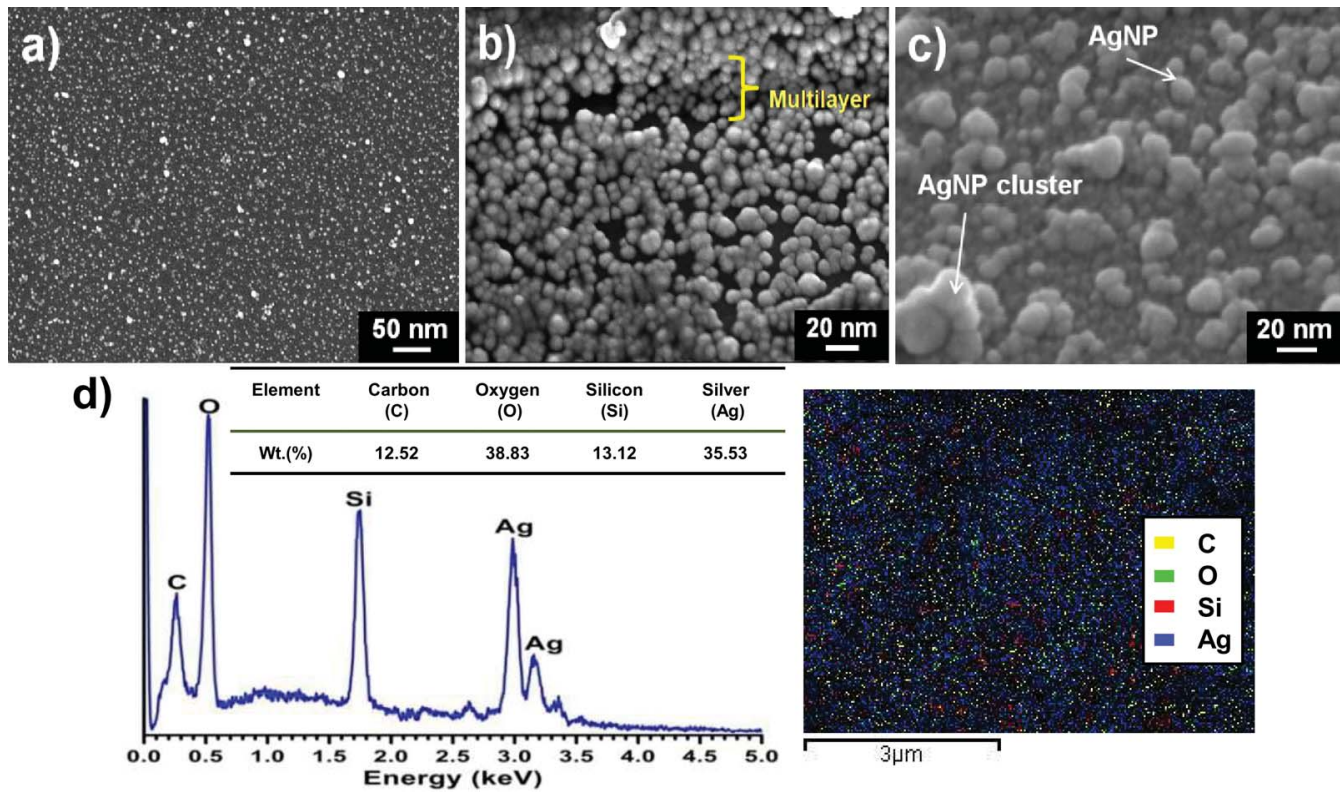

Fig. 3 FEG-SEM images of silver nanoparticles (AgNPs) immobilized on the amine-modified glass surface (a) indicating a highly dense and uniform immobilization of silver nanoparticles on the glass surface. (b) Formation of multiple layers of silver nanoparticles on the silanized glass substrate, possibly due to interactions between AgNPs and both primary and secondary amines on the aminosilane molecules. Oligomerization of the aminosilane might also contribute to this to an extent. (c) Tilted $\left(21^{\circ}\right)$ cross-sectional morphology of the substrate depicting silver nanoparticles (size, 10-15 nm) with a few AgNP clusters (size, 40-60 nm) formed during the immobilization step. (d) Semi-quantitative estimation of the surface composition, as determined by EDX, showing $35.6 \%$ (\% by wt) of the antimicrobial surface occupied by elemental silver (left panel). Elemental mapping (right panel) for a selected region $\left(5 \times 5 \mu \mathrm{m}^{2}\right.$ ), indicating high deposition of silver nanoparticles (blue) with the presence of other elements, i.e., carbon (yellow), oxygen (green), and silicon (red).
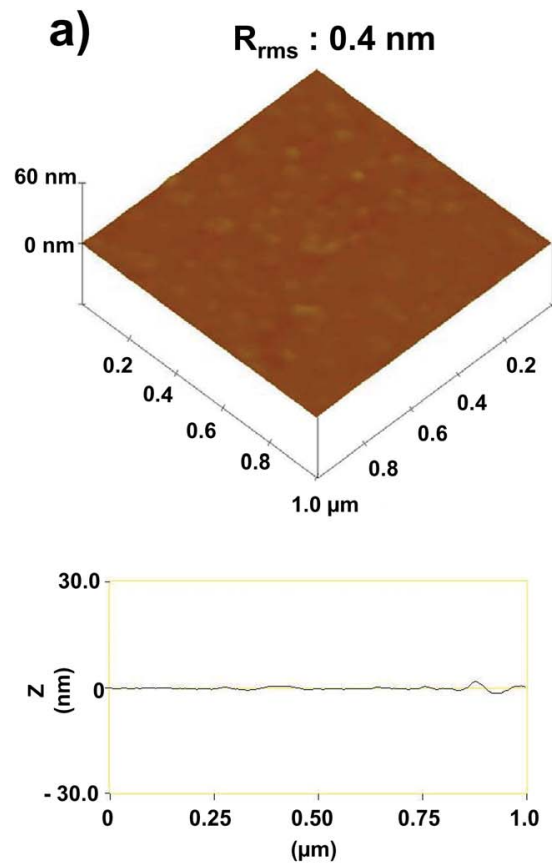
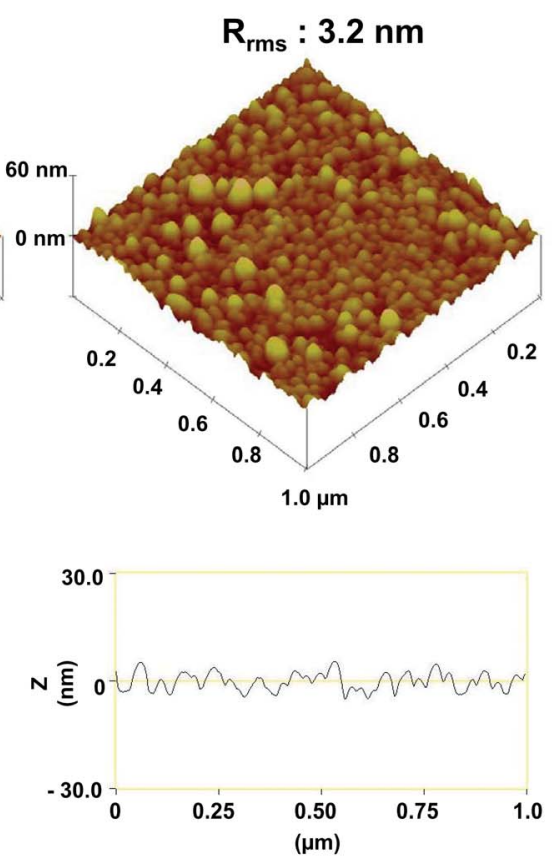
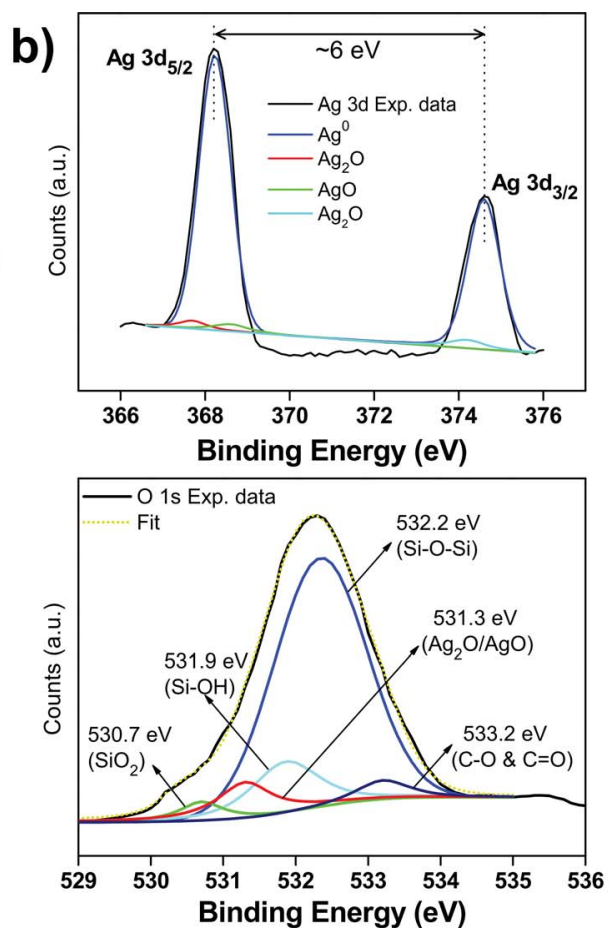

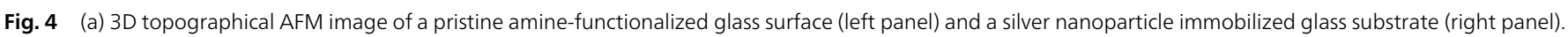

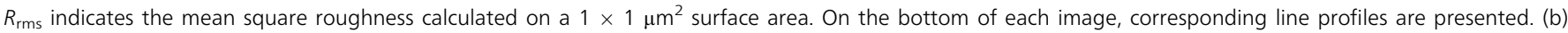

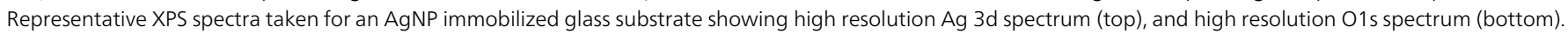


estimated according to the equation; $R_{\mathrm{obs}}=4\left(R_{\mathrm{t}} R_{\mathrm{p}}\right)^{1 / 2}$, where $R_{\mathrm{obs}}, R_{\mathrm{t}}$ and $R_{\mathrm{p}}$ denotes the observed particle radius, tip radius (10 nm, manufacturer specification) and actual radius of the particle, respectively. ${ }^{37}$ As a result, for an observed particle diameter of $52 \mathrm{~nm}$ (i.e., $R_{\mathrm{obs}}=26 \mathrm{~nm}$ ), the true particle diameter was calculated as $8.5 \mathrm{~nm}$ (i.e., $R_{\mathrm{t}}=4.23 \mathrm{~nm}$ ) which matches well with that observed through FEG-TEM $(8.6 \mathrm{~nm})$. Quantification using inductively coupled plasma-atomic emission spectroscopy (ICP-AES) revealed the total silver content on the glass substrate $\left(2 \mathrm{~cm}^{2}\right.$, total surface area) to be $3.26 \mu \mathrm{g} \mathrm{cm}{ }^{-2}$, which is indicative of a dense immobilization of AgNPs on the surface. In contrast, Pallavicini and coworkers ${ }^{22}$ reported monolayer deposition of silver nanoparticles on a thiol-modified silica surface and demonstrated $\sim 10$ times lower silver deposition $\left(0.357 \mu \mathrm{g} \mathrm{cm}^{-2}\right)$. The higher density observed in our study can be attributed to a greater abundance of amine groups with the crosslinker used, such that more anchoring sites are available for AgNPs to attach/immobilize.

The oxidation state of immobilized silver nanoparticles (AgNPs) was analyzed using XPS, a surface sensitive technique, to determine if any thin oxide layer was formed over the surface of AgNPs when exposed to ambient conditions. The high resolution Ag 3d XPS spectrum is shown in Fig. 4b (top). The binding energies of $\mathrm{Ag} 3 \mathrm{~d}_{3 / 2}$ and $\mathrm{Ag} 3 \mathrm{~d}_{5 / 2}$ at $368.4 \mathrm{eV}$ and $374.5 \mathrm{eV}$, respectively and the splitting of the $3 \mathrm{~d}$ doublet of $\mathrm{Ag}$ was $\sim 6 \mathrm{eV}$, indicating the existence of AgNPs at their $\mathrm{Ag}^{0}$ state. $^{38}$ The high resolution $\mathrm{Ag} 3 \mathrm{~d}$ spectrum could be deconvoluted including three additional peaks at binding energies of 367.7, 368.8 , and $374.2 \mathrm{eV}$, thereby indicating the presence of small proportions of $\mathrm{AgO}$, and $\mathrm{Ag}_{2} \mathrm{O}$ along with metallic silver. ${ }^{39,40}$

To verify the presence of an oxide layer on the immobilized AgNPs, a high-resolution $\mathrm{O}$ 1s spectrum was further analysed. The deconvoluted $\mathrm{O} 1 \mathrm{~s}$ spectrum appeared to be more complex. This is expected since various functional groups present on the AgNP-glass substrate contribute to several oxygen species. As shown in Fig. 4b (bottom), five different peaks were fitted, which can be assigned to the presence of $\mathrm{SiO}_{2}(530.7 \mathrm{eV})$ and $\mathrm{Si}-\mathrm{OH}$ $(531.9 \mathrm{eV})$ groups on the glass surface. The strongest peak at $532.2 \mathrm{eV}$ belongs to oxygen associated with the siloxane bond ( $\mathrm{Si}-\mathrm{O}-\mathrm{Si}$ ) formed in polymerized silane. At $533.2 \mathrm{eV}$, a small peak is ascribed to the carboxyl group $\left(-\mathrm{CO},-\mathrm{COO}^{-}\right)$of citrate molecules present on the surface of AgNPs to stabilize them. ${ }^{\mathbf{4 1}}$ The $\mathrm{O}$ 1s peak near $531.3 \mathrm{eV}$ is attributed to a mixture of $\mathrm{AgO}$ and $\mathrm{Ag}_{2} \mathrm{O}$, where $\mathrm{Ag}^{+}$exists as the dominant species. ${ }^{42}$ Thus, although most of the immobilized nanoparticles predominantly exist in their $\mathrm{Ag}^{0}$ oxidation state, a small fraction of oxidized silver also exists under ambient conditions. ${ }^{43}$ The presence of an oxide layer on the AgNP surface is reported to facilitate controlled release of $\mathrm{Ag}^{+}$ions and is responsible for their antibacterial activity. ${ }^{44}$

Since, microbial adherence to an antimicrobial surface depends on its hydrophobic/hydrophilic nature, ${ }^{45}$ the wettability of AgNP-glass was observed through static water contact angle measurement. For comparison, the water contact angle was measured for the cleaned glass surface after: (i) silanol site generation; (ii) the silanization procedure; and (iii) nanoparticle immobilization. Interestingly, the contact angle for the glass with silanol sites was found to be $36.4^{\circ}( \pm 3.4)$, which increased to $63.7^{\circ}( \pm 2.3)$ after the silanization procedure and finally decreased to $48.5^{\circ}( \pm 2.6)$ after silver nanoparticle immobilization on the glass surface, i.e., AgNP-glass substrate. The probable reason for an increase in water contact angle could be the presence of free alkyl chains of the silane layer, which imparts a more hydrophobic character to the surface after the silanization step. ${ }^{34}$ Also, the siloxane bond formation between the glass surface and amino-silane layer caused a significant reduction in the hydrophilic silanol sites (-OH groups), and thus showed an increased water contact angle with a more hydrophobic nature. Subsequently, AgNP immobilization may have caused spatial charge distribution on the surface of the silane layer, which made the surface hydrophilic, i.e., decreased the water contact angle. Thus, favorable electrostatic interactions at the nano-bio interface (i.e., between the nanoparticle and bacteria) may be expected.

\subsection{Strain specific disinfection studies}

Fig. 5 represents strain specific disinfection potential of the AgNP-glass substrate against two Gram negative Escherichia coli strains, MTCC 443 and MTCC 739, and one Gram positive Bacillus subtilis strain, MTCC 441, in both deionized water and phosphate buffer medium. The chlorine-free phosphate buffer medium was considered in order to avoid $\mathrm{AgCl}$ formation during silver ion release from the antimicrobial surface, which could adversely affect the antibacterial potential of the surface. The tests were performed independently at two different initial

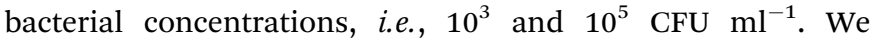
demonstrated AgNP-glass surface to be bactericidal for all the three strains and complete disinfection could be achieved within two hours for all the test conditions. Among the bacterial strains selected in the current study, E. coli MTCC 443 was found to be the most sensitive while $E$. coli MTCC 739 was least sensitive towards the AgNP-glass surface. B. subtilis MTCC 441 exhibited moderate sensitivity towards the immobilized AgNP containing surface. It was noted that the relative sensitivity of these strains to AgNP-glass substrate was in concurrence with previous studies that used colloidal AgNPs. ${ }^{46}$ At an initial count of $10^{3} \mathrm{CFU} \mathrm{ml} \mathrm{m}^{-1}$, complete disinfection was obtained in 50 minutes, 80 minutes and, 60 minutes against $E$. coli MTCC 443, E. coli MTCC 739, and B. subtilis MTCC 441, respectively, in deionized water. At a higher initial cell count $\left(10^{5} \mathrm{CFU} \mathrm{ml}^{-1}\right)$, this duration was prolonged to 90,120 and 90 minutes for the respective microbial strains.

Interestingly, no significant reduction in antibacterial activity was observed in phosphate buffer medium (which mimics physiological conditions) as compared to that in deionized water. Therefore, our immobilization procedure may also be utilized for coating surgical devices and implants.

\subsection{Antimicrobial efficacy and silver release from the surface and its ecotoxicological implications}

A material with sustained antimicrobial efficacy that can be reused a number of times is desirable for disinfection applications. However, for some nano-silver based composite materials 

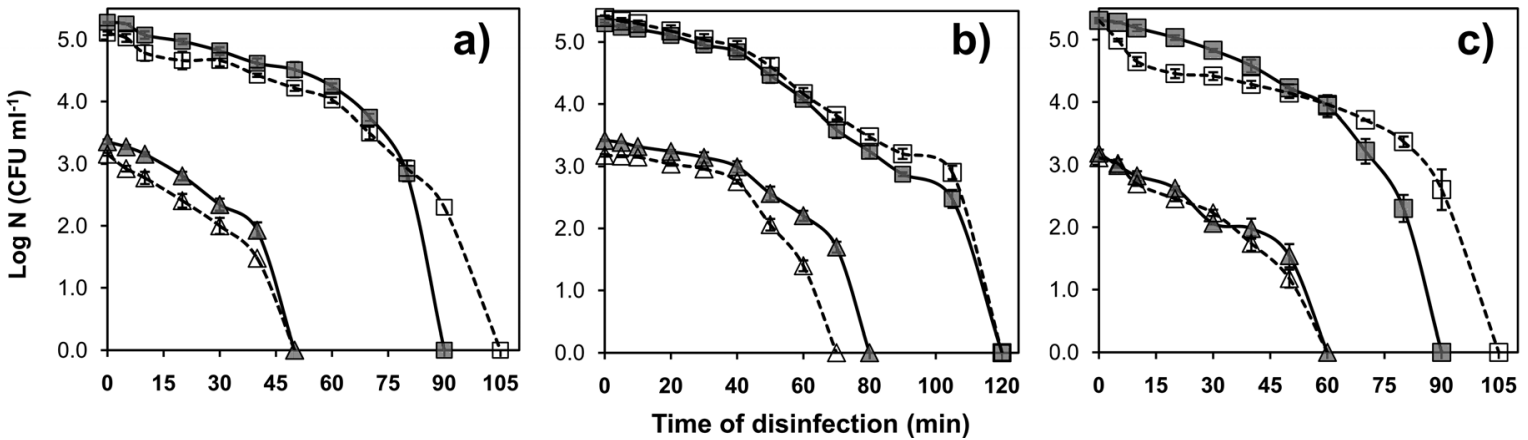

Fig. 5 Strain specific disinfection potential of the AgNP-glass substrate $\left(1 \times 1 \mathrm{~cm}^{2}\right)$ against (a) E. coli MTCC 443, (b) E. coli MTCC 739, and (c) B. subtilis MTCC 441 strains. For each strain, disinfection kinetics were tested at an initial concentration of $\sim 10^{3} \mathrm{CFU} \mathrm{ml}^{-1}$ (triangle) and $\sim 10^{5} \mathrm{CFU} \mathrm{ml} l^{-1}$ (square) in both, deionized water (continuous line) and phosphate buffer medium (dashed line).

the bactericidal efficacy is reported to progressively decrease on repeated use, due to silver ion release. ${ }^{17}$ In contrast, we show that for our AgNP-glass substrate, complete disinfection was still achieved within 50 minutes (initial bacterial concentration of $\sim 10^{3} \mathrm{CFU} \mathrm{ml}{ }^{-1}$ ) even when it was used for the eleventh time (Fig. 6a). It is worth mentioning that although multiple usage affected the disinfection kinetics, the extent of disinfection at 50 minutes was comparable. As shown in Fig. 6b, the total concentration of silver released after 60 minutes duration was $16 \pm 1.3,20 \pm 0.9,25.1 \pm 0.78,19.2 \pm 0.04$, and $11 \pm 1.1 \mathrm{ppb}$ for the 2nd, 4th, 6th, 8th, and 10th use, respectively. This trend could have been observed due to various reasons. One of the probable reasons could be related to the morphology of the antibacterial surface, i.e., the immobilized AgNPs probably exist in a multilayer form, as shown by FEG-SEM analysis. The initial increase in silver ion release up to $25 \mathrm{ppb}$ indicates that the surface exposed nanoparticles come in contact with water, and are preferentially solvated such that a relatively higher concentration is released. Another reason could be that smaller AgNPs on the substrate undergoes faster dissolution than larger particle. ${ }^{18}$ The variation in silver release upon multiple reuse could also be due to variation in the silver oxide coverage on the immobilized nanoparticles. ${ }^{44}$ After the same AgNP immobilized substrate was repeatedly used six times, significant variation in the size of silver nanoparticles on the surface was observed through FEG-SEM analysis (results not shown). These clusters were responsible for the lower release of silver ions during its subsequent use. Morones and coworkers ${ }^{10}$ also reported this trend where AgNPs at a concentration less than $5 \mu \mathrm{M}$ caused rapid release of $\mathrm{Ag}^{+}$due to faster dissolution, whereas further dissolution and release of $\mathrm{Ag}^{+}$was hindered due to the formation of $\mathrm{Ag}$ clusters.

The initial rate of $\mathrm{Ag}^{+}$release was same irrespective of prior usage. Even when the silver release was as low as $10.9 \mathrm{ppb}$ (after the 11th use), sufficient disinfection was achieved (Fig. 6b). In this study, the maximum amount of silver released from the AgNP-glass substrate was found to be $25.1 \mathrm{ppb}$, which constituted $\sim 1.15 \%$ of the total amount of silver immobilized on the AgNP-glass substrate.

Furthermore, to study the possible role of dissolution of AgNPs in deionized water on multiple usage, the same AgNPglass substrate was characterized using AFM at two different stages, i.e., freshly prepared (Fig. 7b) and after the 11th reuse (Fig. 7c), and were compared with bare silanized glass surface (Fig. 7a). An examination of the surface topography revealed adequate immobilization of densely placed AgNPs over the
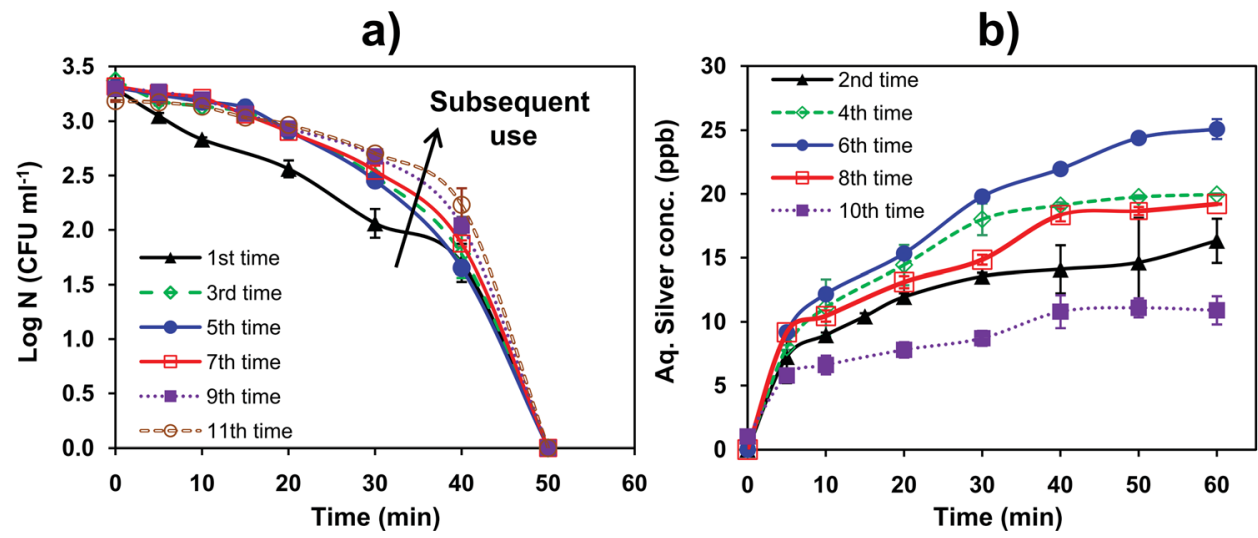

Fig. 6 (a) Antimicrobial efficacy of a single AgNP-glass substrate in a $100 \mathrm{ml}$ reactor containing $\sim 10^{3} \mathrm{CFU} \mathrm{ml}^{-1}$ E. coli MTCC 443 cells. The arrow indicates slower disinfection kinetics after multiple reuse. (b) Silver release profile for the same AgNP-glass substrate, when used repeatedly in a $100 \mathrm{ml}$ reactor (without bacteria). 
entire surface. Also, all AgNPs were spherical in shape and a few AgNP clusters were also seen. While in Fig. 7c, there were a few regions on the AgNP-glass surface either devoid of silver nanoparticles, or containing silver clusters of irregular shape. Therefore, it was expected that there might be some variation in the surface density of the AgNP-glass substrate when exposed repeatedly to the aqueous environment. The AFM micrograph showed a reduction in surface coverage from $15.8 \%$ to $13.3 \%$ after the substrate was reused 11 times (Fig. S5†). This clearly indicates the dissolution of AgNPs from the surface and thereby, varying disinfection and silver release kinetics with repeated use. Reduced silver content in the AgNP-glass substrate is, therefore, attributed to their dissolution with repeated use, where leaching may have occurred either in nanoparticle/ionic form.

Although the silver released is below the acceptable limit and does not pose a health risk to human beings, ${ }^{47}$ silver nanoparticles/ions in the range of 10-25 ppb may have ecotoxicological implications. The toxicity of AgNPs to any organism depends on their dose or concentration, size, capping agent used, biodistribution, bioavailability and water chemistry. ${ }^{48-53}$ The general consensus is that both silver ions and silver nanoparticles display similar toxicity to fish and other aquatic organisms at ppm levels, ${ }^{\mathbf{4 8}}$ whereas at lower concentrations (ppb level) AgNPs display lower acute toxicity than silver ions. ${ }^{54}$ Toxicological studies using zebrafish embryos demonstrated that both silver ions and AgNPs displayed acute mortality and severe physical deformities at a concentration of 10100 ppm. ${ }^{51,52}$ Long-term exposure of AgNPs (3-20 nm size) to zebrafish embryos at a concentration exceeding $50 \mathrm{ppm}$ resulted in their accumulation in heart, lungs, yolk and blood. ${ }^{51}$ Griffitt et al. ${ }^{55}$ reported AgNPs ( $\sim 26 \mathrm{~nm}$ size) to be 300 fold less toxic (based on $48 \mathrm{~h} \mathrm{LC}_{50}$ ) than dissolved $\mathrm{Ag}$ towards adult zebrafish. Similarly, silver ions displayed a very high mortality rate against fathead minnow embryos ( $\left.96 \mathrm{~h} \mathrm{LC}_{50}=15 \mathrm{ppb}\right)$ as compared to AgNPs ( $96 \mathrm{~h} \mathrm{LC}_{50}=1.34 \mathrm{ppm}$, for AgNPs of average size 31-50 nm). ${ }^{56}$ The uptake of AgNPs by an aquatic crustacean, Daphnia magna was found to be four times lower than that of silver ions at a concentration below $40 \mathrm{ppb} .^{57}$ At low doses, typical sub-lethal toxic effects on fish can be manifested by changes in gill pathology, delayed hatching period, malformed notochord, weak heartbeat, and curved tails. ${ }^{51,52,58}$ Recently, Graffitt and coworkers ${ }^{59}$ demonstrated chronic effects of various concentrations of $\operatorname{AgNPs}(5,15,25$, and $50 \mathrm{ppb}$, for AgNPs of size $\sim 3.1 \mathrm{~nm}$ ) on adult zebrafish exposed over 28 days. The results demonstrated that long-term exposure to AgNPs significantly facilitated their internalization on gill tissues, however, no alteration in gill morphology was observed. Moreover, AgNPs at $50 \mathrm{ppb}$ concentration showed adverse effect on gene expression patterns for genes that code for DNA damage repair, cellular restructuring, and developmental processes. Although $5 \mathrm{ppb}$ AgNPs displayed minor sub-lethal effects (i.e., epithelial proliferation) on zebrafish gills, no significant change in morphology was observed at AgNP concentrations between 5 and 15 ppb. In another study, citrate is reported to be a less-toxic capping agent compared to others such as, gum arabic and polyvinylpyrrolidone. ${ }^{54}$ Capping agents can also reduce the toxic effects of nanosilver by controlling release of $\mathrm{Ag}^{+}$ion from the surface. ${ }^{53}$ Smaller sized nanoparticles have been found to be more toxic to aquatic organisms. ${ }^{52,53}$ Some fungal (Penicillium fellutanum $)^{\mathbf{6 0}}$ and protozoan (Tetrahymena thermophila) ${ }^{\mathbf{6 1}}$ species can convert $\mathrm{Ag}^{+}$ions into AgNPs of comparatively large size, as a survival mechanism in contaminated environments, and can overcome silver toxicity. Based on the amount of silver released from the AgNP-glass substrate, some sub-lethal effects on aquatic organisms may be expected on long-term exposure.

\subsection{Mechanism of bactericidal action}

The mechanism of bactericidal action can be due to any of the following: (i) direct contact with immobilized silver nanoparticles, (ii) contact with silver nanoparticles released into the solution as colloids, and (iii) mediated via silver ions released either from colloidal AgNPs in the solution or immobilized nanoparticles. To determine the mechanism, the disinfection profile of a chloridized silver plate (effectively serving as an infinite source of $\mathrm{Ag}^{+}$ions), a pure silver plate, and AgNPs in colloidal form were compared with the disinfection profile of an AgNP-glass substrate. Fig. 8a-c clearly showed that AgNP-glass substrate exhibited better disinfection, much beyond that of substrates that released silver in its ionic form only (viz. $\mathrm{AgCl}$ plate, Ag plate), although the amount of silver in solution was much greater (70-80 ppb) in these instances. The disinfection using only colloidal nanoparticles was also substantially slower than using the AgNP-glass substrate, even though the systems contained approximately the same number of nanoparticles of similar size and morphology (Fig. 8c). The mass of nanoparticles recovered from both the systems as revealed through
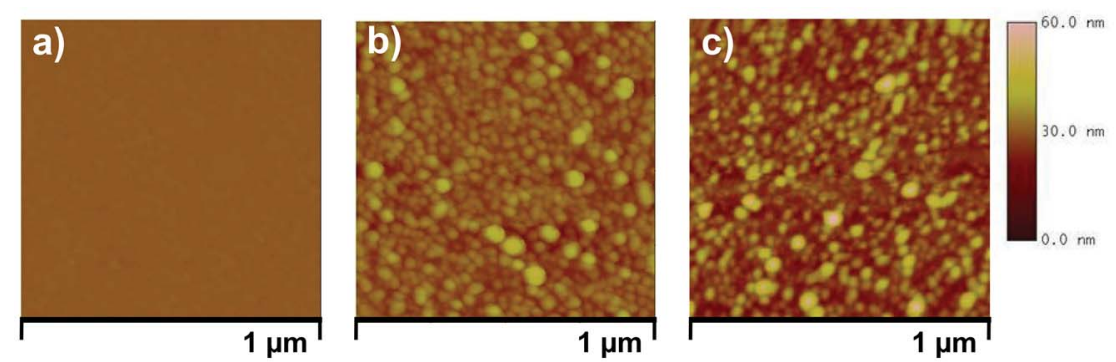

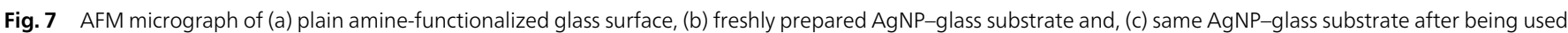
11 times in deionized water. 
nitric acid digestion and ICP-AES analysis were found to be identical $\left(3.07 \times 10^{-2} \mathrm{mg}\right.$, based on triplicate analysis). The AgNP-glass substrate demonstrated better disinfection potential, because it retarded oxidation and aggregation of the immobilized AgNPs.

Lv et al. ${ }^{19}$ also demonstrated higher stability of immobilized AgNPs as compared to the colloidal AgNPs, which in turn, prevented oxidation/aggregation of the immobilized nanoparticles and was responsible for their long-term antimicrobial activity. For practical disinfection applications, immobilization could also subdue the toxic effects on consumption of this disinfected water due to less carry-over of free AgNPs into the aqueous medium.

Since silver ions released from the $\mathrm{AgCl} / \mathrm{Ag}$-plate exhibited slower disinfection even at higher concentrations, it may be concluded that silver ions released from colloidal/immobilized AgNPs might not be the primary mechanism of bactericidal action, unless the silver ions released from nanoparticles are somehow different in nature. The slower disinfection rate exhibited by AgNPs in colloidal form seems to be contrary to this as well. Comparing the nature of disinfection of colloidal nanoparticles versus immobilized nanoparticles it may further be concluded that nanoparticles in the colloidal form lose their efficacy to some degree. This seems to be possible only if nanoparticles spontaneously aggregate in solution ${ }^{7}$ (thereby reducing their surface-to-volume ratio) or they are internalized by bacterial cells ${ }^{62}$ (thereby rendering those nanoparticles harmless to other live bacteria).
In order to verify this, the bacterial cells (E. coli MTCC 443 strain) treated with immobilized AgNPs and colloidal AgNPs were analyzed using FEG-TEM. For the immobilized AgNP treated cells, AgNPs were confined only to the cell membrane (encircled in red and indicated by arrow) as shown in Fig. 9a. For cells treated with colloidal AgNPs, the AgNPs were found both near the bacterial membrane and also in the interiors of the cell (Fig. 9b, inset). The scanning tunneling electron microscopic (dark field STEM) analyses of the corresponding samples (Fig. 9c and d) supported the above results, where a few bright spots near the cell membrane region indicate the presence of AgNPs. For the cells treated with colloidal AgNPs (Fig. 9d), silver nanoparticles were invariably present all over the cell in comparatively higher amounts and tended to form aggregates after their internalization inside the cell (indicated by arrows). Similar micrographs have been reported earlier and thus validate the presence of AgNPs inside bacteria using TEM/STEM. ${ }^{10,63}$ Diffraction ring patterns (Fig. 9d inset) also demonstrated presence of crystalline silver.

FEG-SEM analysis revealed that AgNPs were totally absent on cells treated with immobilized AgNPs (Fig. 9e); whereas they were present over the entire surface for cells treated with colloidal AgNPs (Fig. 9f). EDX results indicated that silver was detected only in the cell membrane region for the cells treated with immobilized AgNPs, whereas its presence was detected at all three selected regions (on the cell membrane, just inside the cell membrane, and in the cell interiors) in varied amounts for the cells exposed to colloidal AgNPs (Fig. 9g). As more and more a)

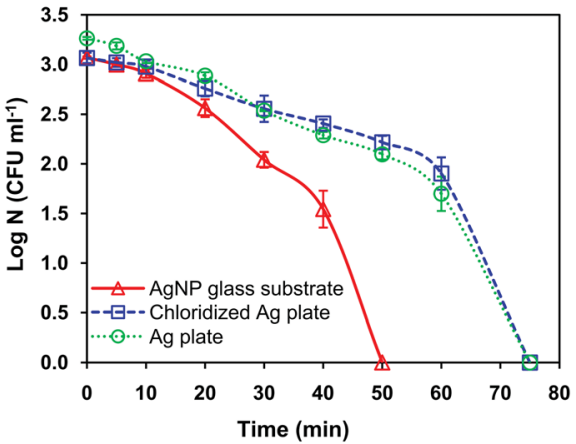

b)

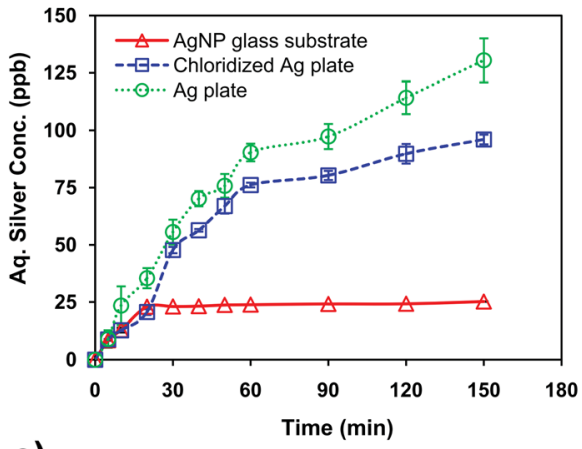

c)

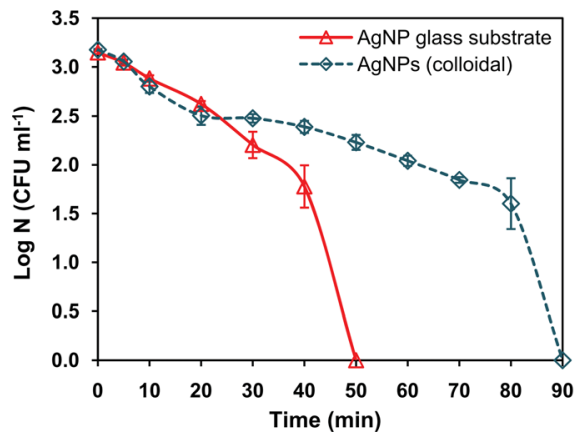

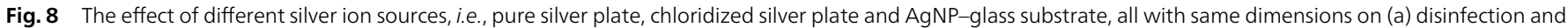

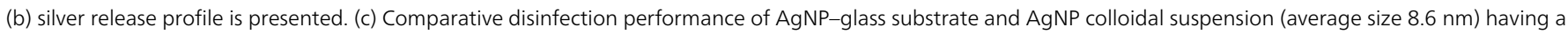
similar amount of silver (i.e., $3.07 \times 10^{-2} \mathrm{mg}$ ). The tests were carried out against the E. coli MTCC 443 strain. 

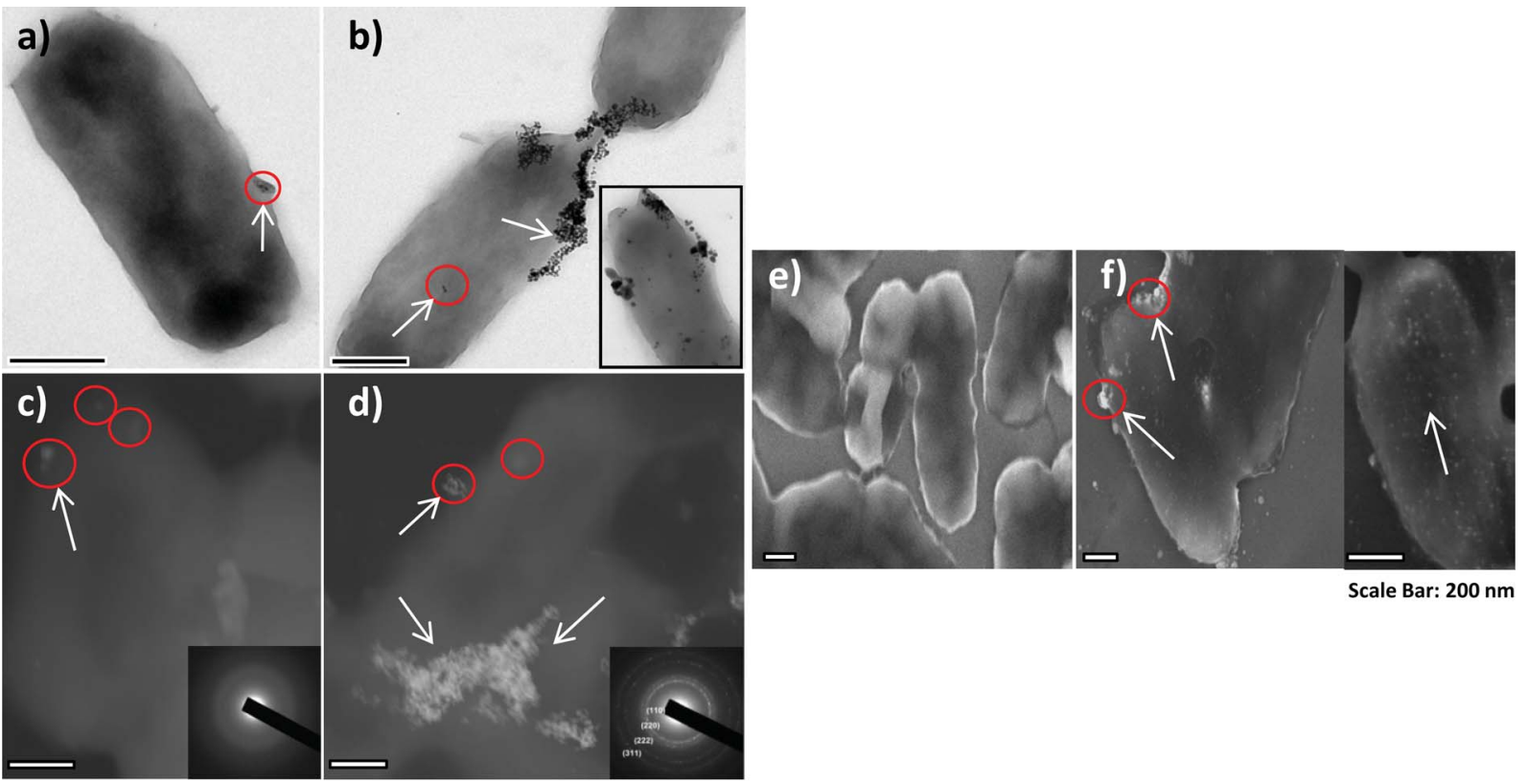

Scale Bar: 200 nm

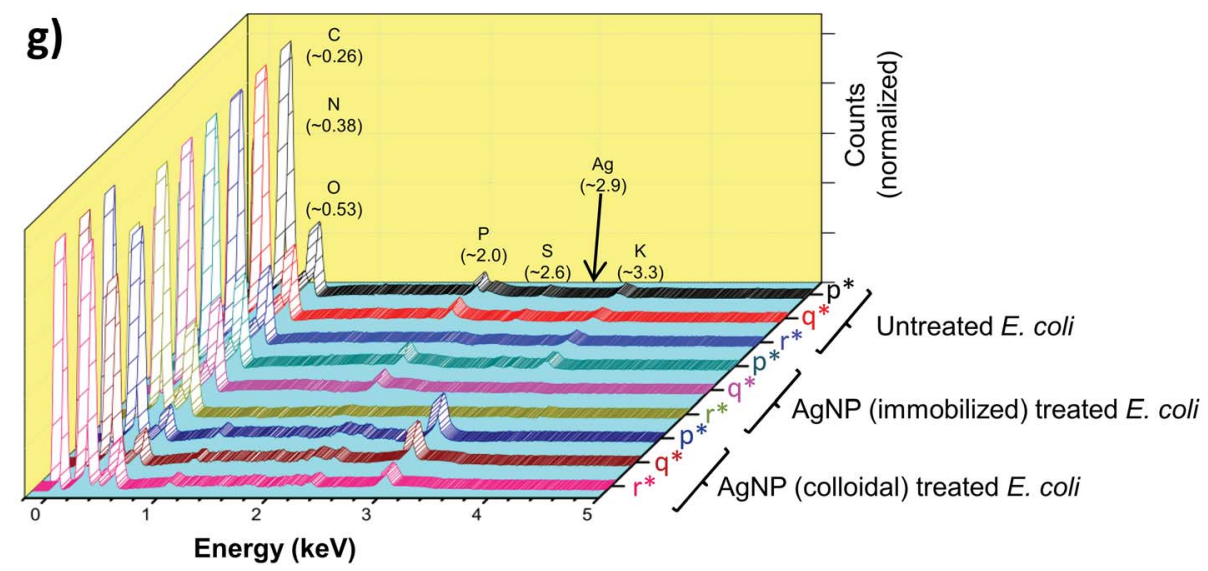
* EDX analyses were taken at different locations in the bacteria: $p^{*}$ - cell membrane; $q^{*}$ - just inside the cell
membrane, and $r^{*}$ - interiors (center) of cell. At each location, EDX analysis was performed using a line scan
having an average of six points over a scan.

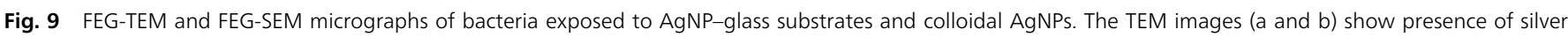

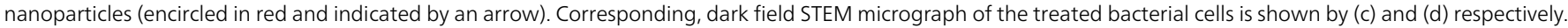

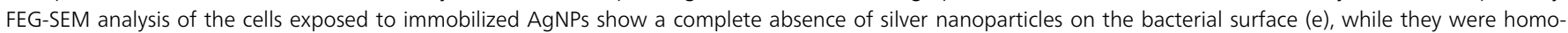

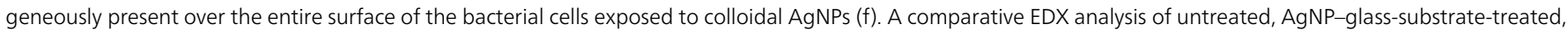

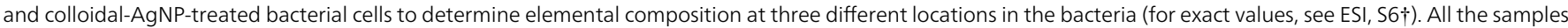
were post-treatment, zero viable count $(\mathrm{g})$.

AgNPs were sequestered inside the cells and were not accessible to the other cells, disinfection kinetics was slower than for the immobilized AgNPs. In contrast, AgNPs in their immobilized form interacted without getting incorporated within cells and thus demonstrated a more effective bactericidal action.

Sotiriou and Pratsinis ${ }^{\mathbf{1 4}}$ also demonstrated that immobilized AgNPs within a size range of $4<x<10 \mathrm{~nm}$ (where $x=$ average size of immobilized AgNPs) may act through both release of $\mathrm{Ag}$ ions and direct contact behavior. It has also been proposed that AgNP-specific generation of reactive oxygen species (ROS) contributes towards more potent bacterial toxicity. ${ }^{64}$ However, the evidence we present (using $8.6 \pm 1.2 \mathrm{~nm}$ AgNPs) indicates that direct contact plays a predominant role in disinfection.

\section{Conclusion}

Silver nanoparticles were immobilized on an amine-functionalized glass substrate, which showed promising disinfection ability by acting predominantly via contact-mode action. The silver nanoparticle immobilized glass surface showed an extraordinary and effective antimicrobial behavior, which caused $100 \%$ mortality against both E. coli and B. subtilis 
bacterial strains within two hours. With repeated use, the substrate displayed similar disinfection performance indicating an efficient immobilization protocol for silver nanoparticles deposited on the glass surface $\left(3.26 \mu \mathrm{g} \mathrm{cm} \mathrm{cm}^{-2}\right)$, without compromising their disinfection potential. Immobilized silver nanoparticles on this surface could minimize the toxicity issues towards mammalian cells by avoiding excess release of AgNPs into solution. Therefore, an AgNP-glass substrate with dual functionality as well as reduced silver release may prove to be an effective nano antimicrobial material. Here, we propose that this AgNP-glass substrate which is found to be effective for disinfection applications may also be employed in antimicrobial surfaces and coatings, especially in surgical devices and synthetic implants.

\section{Acknowledgements}

The authors gratefully acknowledge the Sophisticated Analytical Instrument Facility (SAIF), and IIT-Bombay Central facility (SPM/AFM, XRD, XPS (ESCA), Zeta potential, and FEG-TEM) for characterization studies. The authors thank Prof. I. Samajdar, IIT Bombay for his help in interpreting the TEM/SEM images, and for XRD data analysis. This study was partially funded by Nanomission, DST, Govt of India.

\section{References}

1 M. Mahmoudi and V. Serpooshan, ACS Nano, 2012, 6, 2656.

2 A. Kumar, P. K. Vemula, P. M. Ajayan and G. John, Nat. Mater., 2008, 7, 236.

3 P. Gunawan, C. Guan, X. Song, Q. Zhang, S. S. J. Leong, C. Tang, Y. Chen, M. B. Chan-Park, M. W. Chang, K. Wang and R. Xu, ACS Nano, 2011, 5, 10033.

4 X. Chen and H. J. Schluesener, Toxicol. Lett., 2008, 176, 1.

5 P. V. Asharani, G. L. Kah Mun, M. P. Hande and S. Valiyaveettil, ACS Nano, 2009, 3, 279.

6 S. W. P. Wijnhoven, J. G. M. Peijnenburg Willie, C. A. Herberts, W. I. Hagens., A. G. Oomen, E. H. W. Heugens, B. Roszek, J. Bisschops, I. Gosens, M. D. Van De, S. Dekkers, J. W. H. De, M. van Zijverden, J. A. M. Sips Adriënne and R. E. Geertsma, Nanotoxicology, 2009, 3, 109.

7 X. Li and J. J. Lenhart, Environ. Sci. Technol., 2012, 46, 5378. 8 B. D. Gusseme, T. Hennebel, E. Christiaens, H. Saveyn, K. Verbeken, J. P. Fitts, N. Boon and W. Verstraete, Water Res., 2011, 45, 1856.

9 A. Gupta and S. Silver, Nat. Biotechnol., 1998, 16, 888.

10 J. R. Morones, J. L. Elechiguerra, A. Camacho, K. Holt, J. B. Kouri, J. T. Ramirez and M. J. Yacaman, Nanotechnology, 2005, 16, 2346.

11 T. M. Benn and P. Westerhoff, Environ. Sci. Technol., 2008, 42, 4133.

12 S. Mukherji, J. Ruparelia and S. Agnihotri, in Nanoantimicrobials-Progress and Prospects, ed. N. Cioffi and M. Rai, Springer-Verlag Berlin, Heidelberg, 2012, ch. 8.

13 S. Agnihotri, S. Mukherji and S. Mukherji, Appl. Nanosci., 2012, 2, 179.
14 G. A. Sotiriou and S. E. Pratsinis, Environ. Sci. Technol., 2010, 44, 5649.

15 P. Jain and T. Pradeep, Biotechnol. Bioeng., 2005, 90, 59.

16 W. L. Chou, D. G. Yu and M. C. Yang, Polym. Adv. Technol., 2005, 16, 600.

17 X. Cao, M. Tang, F. Liu, Y. Nie and C. Zhao, Colloids Surf., B, 2005, 81, 555.

18 A. Nagy, A. Harrison, S. Sabbani, R. S. Munson, Jr, P. K. Dutta and W. J. Waldman, Int. J. Nanomed., 2011, 6, 1833.

19 M. Lv, S. Shao, H. Yao, Q. Huang, W. Hu, D. Li, C. Fan and S. T. Lee, Adv. Mater., 2010, 22, 5463.

20 P. K. Jal, S. Patel and B. K. Mishra, Talanta, 2004, 62, 1005.

21 K. H. Wu, Y. C. Chang, W. Y. Tsai, M. Y. Huang and C. C. Yang, Polym. Degrad. Stab., 2010, 95, 2328.

22 P. Pallavicini, A. Taglietti, G. Dacarro, Y. A. Diaz-Fernandez, M. Galli, P. Grisoli, M. Patrini, G. S. D. Magistris and R. Zanoni, J. Colloid Interface Sci., 2010, 350, 110.

23 C. H. Ho, J. Tobis, C. Sprich, R. Thomann and J. C. Tiller, Adv. Mater., 2004, 16, 957.

24 V. Sambhy, M. M. MacBride, B. R. Peterson and A. Sen, J. Am. Chem. Soc., 2006, 128, 9798.

25 L. L. Woodyard, T. L. Bowersock, J. J. Turek, G. P. McCabe and J. DeFord, J. Controlled Release, 1996, 40, 23.

26 J. H. Fu, J. Ji, D. Z. Fan and J. C. Shen, J. Biomed. Mater. Res., Part A, 2006, 79A, 665.

27 H. J. Yu, X. Y. Xu, X. S. Chen, T. C. Lu, P. B. Zhang and X. B. Jing, J. Appl. Polym. Sci., 2007, 103, 125.

28 Y. Li, W. K. Leung, K. L. Yeung, P. S. Lau and J. K. S. Kwan, Langmuir, 2009, 25, 13472.

29 Z. Li, D. Lee, X. Sheng, R. E. Cohen and M. F. Rubner, Langmuir, 2006, 22, 9820.

30 S. Kittler, C. Greulich, J. Diendorf, M. Koller and M. Epple, Chem. Mater., 2010, 22, 4548.

31 M. Joshi, M. Goyal, R. Pinto and S. Mukherji, 2nd IEEE-EMBS International summer school and symposium on medical devices and biosensors (ISSS-MDBS), 2004, Hong Kong.

32 D. V. Quang, P. B. Sarawade, A. Hilonga, J. K. Kim, Y. G. Chai, S. H. Kim, J. Y. Ryu and H. T. Kim, Appl. Surf. Sci., 2011, 257, 6963.

33 T. J. Horr and P. S. Arora, Colloids Surf., A, 1997, 126, 113. 34 S. Fiorilli, P. Rivolo, E. Descrovi, C. Ricciardi, L. Pasquardini, L. Lunelli, L. Vanzetti, C. Pederzolli, B. Onida and E. Garrone, J. Colloid Interface Sci., 2008, 321, 235.

35 N. E. Cant, K. Critchley, H. L. Zhang and S. D. Evans, Thin Solid Films, 2003, 426, 31.

36 A. M. Almanza-Workman, S. Raghavan, P. Deymier, D. J. Monk and R. Roop, Colloids Surf., A, 2004, 232, 67.

37 A. Doron, E. Joselevich, A. Schlittner and I. Willner, Thin Solid Films, 1999, 340, 183.

38 B. J. Murray, Q. Li, J. T. Newberg, E. J. Menke, J. C. Hemminger and R. M. Penner, Nano Lett., 2005, 5, 2319.

39 V. G. Pol, D. N. Srivastava, O. Palchik, V. Palchik, M. A. Slifkin, A. M. Weiss and A. Gedanken, Langmuir, 2002, 18, 3352.

40 A. Babapour, B. Yang, S. Bahang and W. Cao, Nanotechnology, 2011, 22, 155602. 
41 Y. Chi, L. Zhao, Q. Yuan, X. Yan, Y. Li, N. Li and X. Li, J. Mater. Chem., 2012, 22, 13571.

42 W. Wei, X. Mao, L. A. Ortiz and D. R. Sadoway, J. Mater. Chem., 2011, 21, 432.

43 M. Schmidt, A. Masson and C. Bréchignac, Phys. Rev. Lett., 2003, 91, 243401.

44 G. A. Sotiriou, A. Meyer, J. T. N. Knijnenburg, S. Panke and S. E. Pratsinis, Langmuir, 2012, 28, 15929.

45 S. Chakraborty, S. Mukherji and S. Mukherji, Colloids Surf., $B, 2010,78,101$.

46 J. P. Ruparelia, A. K. Chatterjee, S. P. Duttagupta and S. Mukherji, Acta Biomater., 2008, 4, 707.

47 World Health Organization, in Guidelines for Drinking Water Quality, 3rd edn, World Health Organization, Geneva, Switzerland, 2004, vol. 1, p. 237.

48 B. J. Shaw and R. D. Handy, Environ. Int., 2011, 37, 1083.

49 I. Blinova, J. Niskanen, P. Kajankari, L. Kanarbik, A. Käkinen, H. Tenhu, O. Penttinen and A. Kahru, Environ. Sci. Pollut. Res., 2012, 20, 3456, DOI: 10.1007/s11356-0121290-5.

50 S. Cunningham, M. E. Brennan-Fournet, D. Ledwith, L. Byrnes and L. Joshi, Environ. Sci. Technol., 2013, 47, 3883, DOI: 10.1021/es303695f.

51 P. V. Asharani, Y. L. Wu, Z. Gong and S. Valiyaveettil, Nanotechnology, 2008, 19, 255102.

52 O. Bar-Ilan, R. M. Albrecht, V. E. Fako and D. Y. Furgeson, Small, 2009, 5, 1897.
53 S. George, S. Lin, Z. Ji, C. R. Thomas, L. J. Li, M. Mecklenburg, H. Meng, X. Wang, H. Zhang, T. Xia, J. N. Hohman, S. Lin, J. I. Zink, P. S. Weiss and A. E. Nel, ACS Nano, 2012, 6, 3745.

54 K. W. H. Kwok, M. Auffan, A. R. Badireddy, C. M. Nelson, M. R. Wiesner, A. Chilkoti, J. Liu, S. M. Marinakos and D. E. Hinton, Aquat. Toxicol., 2012, 120-121, 59.

55 R. J. Griffitt, J. Luo, J. Gao, J. C. Bonzongo and D. S. Barber, Environ. Toxicol. Chem., 2008, 27, 1972.

56 G. Laban, L. F. Nies, R. F. Turco, J. W. Bickham and M. S. Sepúlveda, Ecotoxicology, 2010, 19, 185.

57 C. M. Zhao and W. X. Wang, Environ. Sci. Technol., 2010, 44, 7699.

58 K. J. Lee, P. D. Nallathamby, L. M. Browning, C. J. Osgood and X. H. N. Xu, ACS Nano, 2007, 1, 133.

59 R. J. Griffitt, C. M. Lavelle, A. S. Kane, N. D. Denslow and D. S. Barber, Aquat. Toxicol., 2013, 130-131, 192.

60 K. Kathiresan, S. Manivannan, M. A. Nabeel and B. Dhivya, Colloids Surf., B, 2009, 71, 133.

61 K. Juganson, M. Mortimer, A. Ivask, K. Kasemets and A. Kahru, Environ. Sci.: Processes Impacts, 2013, 15, 244.

62 A. Albanese, P. S. Tang and W. C. W. Chan, Annu. Rev. Biomed. Eng., 2012, 14, 1.

63 T. Klaus, R. Joerger, E. Olsson and C. G. Granqvist, Proc. Natl. Acad. Sci. U. S. A., 1999, 96, 13611.

64 A. Ivask, O. Bondarenko, N. Jepihhina and A. Kahru, Anal. Bioanal. Chem., 2010, 398, 701. 